\title{
Aldosterone is not Involved in the Ventricular Remodeling Process Induced by Tobacco Smoke Exposure
}

\author{
Priscila P. dos Santos ${ }^{a}$ Bruna F. Nogueira ${ }^{a}$ Bruna P. M. Rafacho ${ }^{a}$ Paula S. Azevedo \\ Bertha F. Polegato ${ }^{a}$ Fernanda Chiuso-Minicuccib Camila Bonomo ${ }^{a}$ Meliza G. Roscania \\ Sofia F.G. Zorzella-Pezavento ${ }^{b}$ Suzana E. Tanni ${ }^{a}$ Elenize J. Pereira ${ }^{a}$ Marina P. Okoshi ${ }^{a}$ \\ Sergio A. R. Paiva ${ }^{a}$ Leonardo A. M. Zornoffa Marcos F. Minicuccia
}

aInternal Medicine Department, Botucatu Medical School, Univ Estadual Paulista (UNESP), Botucatu; bepartment of Microbiology and Immunology, Institute of Biosciences, São Paulo State University, Botucatu

\author{
Key Words \\ GLUT4 • Inflammation • Ventricular remodeling • Cigarette smoke
}

\begin{abstract}
Background/Aims: Renin-angiotensin-aldosterone system blockade with a mineralocorticoidreceptor antagonist has not yet been studied in exposure to tobacco smoke (TS) models. Thus, this study investigated the role of spironolactone on cardiac remodeling induced by exposure to tobacco smoke. Methods: Male Wistar rats were divided into 4 groups: a control group (group $\mathrm{C}, \mathrm{n}=11$ ); a group with 2 months of cigarette smoke exposure (group TS-C, $\mathrm{n}=13) ;$ a group that received spironolactone $20 \mathrm{mg} / \mathrm{kg}$ of diet/day and no cigarette smoke exposure (group TS-S, $\mathrm{n}=13$ ); and a group with 2 months of cigarette smoke exposure and spironolactone supplementation (group $S, n=12$ ). The rats were observed for a period of 60 days, during which morphological, biochemical and functional analyses were performed. Results: There was no difference in invasive mean arterial pressure among the groups. There were no interactions between tobacco smoke exposure and spironolactone in the morphological and functional analysis. However, in the echocardiographic analysis, the TS groups had left chamber enlargement, higher left ventricular mass index and higher isovolumetric relaxation time corrected by heart rate compared with the non-TS groups. In vitro left ventricular diastolic function also worsened in the TS groups and was not influenced by spironolactone. In addition, there were no differences in myocardial levels of IFN- $\gamma$, TNF- $\alpha$, IL-10, ICAM-1 and GLUT4 [TS: OR $0.52,95 \%$ CI $(-0.007 ; 0.11)$; Spironolactone: OR $-0.01,95 \% C I(-0.07 ; 0.05)]$. Conclusion: Our data do not support the participation of aldosterone in the ventricular remodeling process induced by exposed to cigarette smoke.
\end{abstract}




\section{Introduction}

Exposure to tobacco smoke is currently the leading cause of preventable death. Approximately 440,000 deaths occur annually in the United States due to smoking [1,2]. In addition to the well-known vascular effects of tobacco, some studies have suggested that this exposure may induce ventricular remodeling [3-10]. Tobacco smoke exposure results in left ventricular enlargement and hypertrophy and systolic and diastolic dysfunction evaluated by in vivo and in vitro techniques [3-10]. The mechanisms involved in this remodeling process are not completely known. Potential mechanisms for these alterations include inflammation $[8,11]$, oxidative stress $[8,11]$, metalloproteinase [5] and mitogen-activated protein kinase activation [6], and hemodynamic and neurohormonal changes, such as renin-angiotensinaldosterone system (RAAS) activation [12].

RAAS blockade has already been studied in cardiac remodeling induced by tobacco smoke. Duarte et al. showed that lisinopril, an angiotensin converting enzyme inhibitor, attenuated left ventricle enlargement, myocyte hypertrophy and systolic dysfunction due to tobacco smoke exposure. In addition, these alterations were not associated with connexin 43 distribution, cytokine production or collagen content [12]. However, RAAS blockade with a mineralocorticoid-receptor antagonist, such as spironolactone, has not yet been studied in tobacco smoke exposure models.

Mineralocorticoid-receptor antagonists have been used in different models of cardiac remodeling. The American Heart Association recommends their use for patients with systolic dysfunction and NYHA heart failure classes III and IV, and for systolic dysfunction after myocardial infarction [13]. Recently, the EMPHASIS-HF study showed that eplerenone reduced hospital admission and cardiovascular and all-cause mortality in patients with heart failure and mild symptoms [14]. Accordingly, the 2011 guideline updates have recommended eplerenone or spironolactone for systolic heart failure patients with NYHA class II symptoms $[15,16]$.

The potential effects of aldosterone blockers are reduced inflammation, decreased collagen amount and attenuated myocyte hypertrophy $[17,18]$. In addition, spironolactone can also influence glucose transport. Lastra et al. showed that low-dose spironolactone improves insulin-stimulated glucose transport in the skeletal muscle of transgenic rats with increased tissue renin-angiotensin system activity [19]. In this study, spironolactone increased expression of insulin receptor substrate and glucose transporter type 4 (GLUT4) [19].

Thus, this study investigated the role of spironolactone on cardiac remodeling induced by tobacco smoke exposure.

\section{Materials and Methods}

All experiments and procedures were performed in accordance with the National Institutes of Health's Guide for the Care and Use of Laboratory Animals and were approved by the Animal Ethics Committee of our institution.

Male Wistar rats that weighed 200-230 g were assigned to 4 experimental groups: a control group (group $C, n=11$ ); a group with 2 months of cigarette smoke exposure (group TS-C, $n=13$ ); a group that received spironolactone $20 \mathrm{mg} / \mathrm{kg}$ of diet/day and no cigarette smoke exposure (group TS-S, n=13); and a group with 2 months of cigarette smoke exposure and spironolactone supplementation (group $S, n=12$ ). The amount of food given was determined by the amount ingested by the exposure to tobacco smoke groups. Water was supplied ad libitum. The rats were observed for 60 days, during which morphological, biochemical and functional analyses were performed. The TS rats were exposed to cigarette smoke in a chamber $(95 \times 80 \times 65$ $\mathrm{cm}$ ) that was connected to a smoking device based on a model published by Wang et al. [20] and adapted by Paiva et al. [21]. The smoke was drawn out of filtered commercial cigarettes (composition per unit: 1.1 mg nicotine, $14 \mathrm{mg}$ tar and $15 \mathrm{mg}$ carbon monoxide) with a vacuum pump and exhausted into the smoking chamber. During the first week, the number of cigarettes was gradually increased from 5 to 10 cigarettes 
over a 30 min period, administered twice each afternoon. Subsequently, 10 cigarettes were used for each exposure, and the rats were exposed to the smoke four times/day: twice in the morning and twice in the afternoon. Thus, the TS groups smoked 40 cigarettes/day. Considering the carboxyhemoglobin levels, this protocol is similar to 3-4 pack/day in human.

\section{Invasive blood pressure measurement}

After the observation period, invasive blood pressure measurement was performed. The rats were lightly anesthetized with an intramuscular (IM) injection of ketamine $(50 \mathrm{mg} / \mathrm{kg})$ and xylazine $(1 \mathrm{mg} / \mathrm{kg})$. An arterial catheter was placed in the left femoral artery to measure the mean arterial pressure (5 rats per group).

\section{Echocardiographic analysis}

After 2 months of exposure, all of the animals were weighed and evaluated by transthoracic echocardiography. The exams were performed using a commercially available echocardiograph (SONOS 2000, Hewlett-Packard Medical Systems, Andover, MA) that was equipped with a 7.5-MHz, phased-array transducer. The imaging was performed with a $60^{\circ}$ sector angle and a $3-\mathrm{cm}$ imaging depth. The rats were lightly anesthetized with an intramuscular (IM) injection of ketamine (50 mg/kg) and xylazine $(1 \mathrm{mg} /$ $\mathrm{kg}$ ). The rats' chests were shaved, and the rats were placed in a left lateral position. Targeted 2-D, M-mode echocardiograms were obtained from short-axis views of the left ventricle (LV) at or just below the tip of the mitral-valve leaflTS and at the level of the aortic valve and left atrium. M-mode images of the LV, left atrium and aorta were recorded on a black-and-white thermal printer (Sony Up-890MD) at a sweep speed of $100 \mathrm{~mm} / \mathrm{s}$. All of the tracings were manually measured with calipers by the same observer using the leading-edge method recommended by the American Society of Echocardiography [22]. The data represent the mean of measurements from at least five consecutive cardiac cycles. The LV end-diastolic dimension (LVDD) and posterior wall thickness (LVWT) were measured at the maximal diastolic dimension, whereas the end-systolic dimension (LVSD) was measured at the maximal anterior motion of the posterior wall. The left atrium was measured at its maximal diameter, and the aorta was measured at the end of diastole. LV systolic function was assessed by calculating the fractional shortening [(LVDD - LVSD)/LVDD x 100] and the ejection fraction $\left[\left(\mathrm{LVDD}^{3}-\mathrm{LVSD}^{3}\right) / \mathrm{LVDD}^{3}\right]$. The transmitral diastolic flow (E and A) velocities were obtained from the apical four-chamber view. The E/A ratio was used as an index of LV diastolic function.

\section{In vitro left ventricular function analysis}

The procedures and measurements were performed following a previously described method [23]. One day after the echocardiographic study, the rats were anesthetized with thiopental sodium (50 mg/kg, i.p.) and given heparin (2000 IU, i.p.). The chest was opened by median sternotomy under artificial ventilation. The entire heart was quickly removed and transferred to a perfusion apparatus (model 830 Hugo Sachs Eletronick-Green-strasse). The ascending aorta was isolated and cannulated for retrograde perfusion with filtered and oxygenated Krebs-Henseleit solution (115mM NaCl, $5.4 \mathrm{mM} \mathrm{KCl}, 2.5 \mathrm{mM} \mathrm{CaCl}, 1.2 \mathrm{mM} \mathrm{MgSO}$, $^{\prime}$ $1.15 \mathrm{mM} \mathrm{NaH}_{2} \mathrm{PO}_{4}, 1.2 \mathrm{mM} \mathrm{Na}_{2} \mathrm{PO}_{4}, 25 \mathrm{mM} \mathrm{NaHCO}_{3}$, and $11 \mathrm{mM}$ glucose) which was maintained at a constant temperature and perfusion pressure $\left(37^{\circ} \mathrm{C}\right.$ and $\left.75 \mathrm{mmHg}\right)$. The main pulmonary artery was cut to vent the right ventricle and a latex balloon was placed into the left ventricle via the mitral valve orifice. The proximal end of the balloon previously attached to a plastic cannula was connected to a three-way stopcock that permitted filling the balloon with saline and emptying it. The ventricular pressure was measured with a 23XL transducer and a WindoGraph $®$ recorder (Gould Inc., Valley View, OH, USA). In the isovolumetrically beating ventricle, paced at 240 beats/min with an artificial pacer, model 79232 (Hugo Sachs Eletronick), the balloon volume was increased in $0.02 \mathrm{ml}$ increments over a diastolic range of $0-25 \mathrm{mmHg}$. The pressure and volume within the balloon were recorded following each increment and corresponded to the left ventricular pressure and volume respectively. After pressure recordings, the hearts were removed from the perfusion apparatus, and left ventricles were weighed.

\section{Morphometric analysis}

At the completion of the functional analyses, the left and right ventricles, including the interventricular septum, were dissected, separated and weighed. Transverse sections of the LV were fixed in $10 \%$ buffered formalin and embedded in paraffin. Five-micron-thick sections were stained with hematoxylin and eosin 
(HE) or the collagen-specific stain, picrosirius red (Sirius red F3BA in aqueous-saturated picric acid). The myocyte cross-sectional area was determined for a minimum of 100 myocytes per HE-stained cross section. The measurements were obtained from digital images (400× magnification) that were collected with a video camera attached to a Leica microscope; the images were analyzed with Image-Pro Plus 3.0 software (Media Cybernetics; Silver Spring, MD). The myocyte cross-sectional area was measured with a digital pad, and the selected cells were transversely cut so that the nucleus was in the center of the myocyte [21]. The interstitial collagen volume fraction was determined for the entire cardiac section that was stained with Picrosirius Red by analyzing the digital images captured under polarized light (200× magnification). The myocardial tissue components were identified according to the following staining patterns: red for collagen fibers, yellow for myocytes and white for interstitium. The collagen volume fraction was calculated as the sum of all of the connective tissue areas divided by the sum of all of the connective tissue and myocyte areas. On average, 35 microscopic fields were analyzed per heart with a $20 \times$ lens. Perivascular collagen was excluded from this analysis [21].

\section{Western blot analysis}

An antibody against GLUT4 [GLUT 4 mouse monoclonal IgG1 (IF8, sc-53566, dilution 1:500, Santa Cruz Biotechnology)] was used. Briefly, frozen LV isolated from the $C(n=6), S(n=6)$, TS-C ( $n=7)$, and TS-S groups $(\mathrm{n}=7)$ were homogenized in a buffer containing $50 \mathrm{mmol} / \mathrm{L}$ potassium phosphate $(\mathrm{pH}=7.0), 0.3 \mathrm{~mol} / \mathrm{L}$ sucrose, $0.5 \mathrm{mmol} / \mathrm{L}$ DTT, $1 \mathrm{mmol} / \mathrm{L}$ EDTA (pH=8), $0.3 \mathrm{mmol} / \mathrm{L}$ PMSF, $10 \mathrm{mmol} / \mathrm{L} \mathrm{NaF}$, and phosphatase inhibitor cocktail (1:100; Sigma-Aldrich). The homogenate was centrifuged at $4^{\circ} \mathrm{C}$ for $20 \mathrm{~min}$ at 12,000 $\times g$. The supernatant was collected, and the total protein content was determined by the Bradford method. These homogenates were also used for cytokine and adhesion molecule analyses.

The samples were subjected to SDS-PAGE electrophoresis. After this procedure, the proteins were electro-transferred to nitrocellulose membranes. Equal loading of the samples $(50 \mu \mathrm{g})$ and even transfer efficiency were monitored through the use of $0.5 \%$ Ponceau $S$ staining of the blotted membrane. The blotted membrane was then blocked ( $5 \%$ nonfat dry milk; $10 \mathrm{mM}$ Tris- $\mathrm{HCl}, \mathrm{pH}=7.6 ; 150 \mathrm{mM} \mathrm{NaCl}$; and $0.1 \%$ Tween 20) for 2 hours at room temperature and incubated with specific antibodies overnight at $4{ }^{\circ} \mathrm{C}$. Binding of the primary antibody was detected by a peroxidase-conjugated secondary antibody (mouse, 1:10,000, for $1.5 \mathrm{~h}$ at room temperature) and developed by enhanced chemiluminescence (Amersham Biosciences) detected by autoradiography. Quantification analysis of the blots was performed using Scion Image software (based on NIH Image). The targeted bands were normalized to GAPDH.

Evaluation of myocardial cytokine and intercellular adhesion molecule 1 (ICAM-1) concentrations

Myocardial cytokine production was measured by ELISA according to the manufacturer's instructions (R\&D Systems), as previously described [24, 25]. Briefly, cardiac homogenate were coated with capture antibodies for IFN- $\gamma$, TNF- $\alpha$, IL-10, and ICAM-1 in 96-well plates (Nunc). Plates were incubated overnight and then blocked during $2 \mathrm{~h}$ with $1 \%$ albumin in PBS. Standard rat cytokines were added and the plates incubated during $2 \mathrm{~h}$. Biotinylated anti-IFN- $\gamma$, anti-TNF- $\alpha$, anti-IL-10, and anti-ICAM were added and the plates were incubated for an additional $2 \mathrm{~h}$ at room temperature. Plates were incubated at room temperature for 30 min with streptavidin and then revealed by adding $\mathrm{H}_{2} \mathrm{O}_{2}+$ OPD (Sigma). Color development was stopped with $\mathrm{H}_{2} \mathrm{SO}_{4}$ and optical density was measured at $492 \mathrm{~nm}$.

\section{Statistical analysis}

The data are expressed as the mean \pm SD and regression coefficients and $95 \%$ confidence interval. To explore the interactions between tobacco smoke exposure and spironolactone, we performed multiple linear regression analyses with robust standard errors. The robust regression analysis provided an alternative to a least squares regression model when the fundamental assumptions were unfulfilled by the nature of the data and data transformation was not possible. We did not perform a two-way ANOVA analysis, because we could not normalize our data. The associations are expressed by the regression coefficients and $95 \%$ confidence interval of the regression coefficients. A p value of less than 0.05 denotes the presence of a significant difference. Data analysis was performed with STATA" 10.0 - Corp (College Station, Texas, USA). 


\begin{tabular}{|c|c|c|c|c|}
\hline \multicolumn{5}{|l|}{$\overline{\text { Panel A }}$} \\
\hline Variables & $\begin{array}{c}\text { Group C } \\
n=11\end{array}$ & $\begin{array}{c}\text { Group } S \\
n=12\end{array}$ & $\begin{array}{c}\text { Group TS-C } \\
n=13\end{array}$ & $\begin{array}{c}\text { Group TS-S } \\
n=13\end{array}$ \\
\hline$\overline{B W},(\mathrm{~g})$ & $392.0 \pm 35.5$ & $395.2 \pm 28.9$ & $386.5 \pm 29.0$ & $374.5 \pm 32.2$ \\
\hline LVEDD/BW, $(\mathrm{mm} / \mathrm{kg})$ & $18.2 \pm 1.8$ & $17.2 \pm 2.1$ & $18.6 \pm 1.2$ & $19.3 \pm 1.7$ \\
\hline LVESD/BW, $(\mathrm{mm} / \mathrm{kg})$ & $8.4 \pm 1.1$ & $7.6 \pm 2.0$ & $8.4 \pm 1.2$ & $8.9 \pm 1.2$ \\
\hline LVWT, $(\mathrm{mm})$ & $1.3 \pm 0.1$ & $1.3 \pm 0.1$ & $1.3 \pm 0.1$ & $1.3 \pm 0.2$ \\
\hline LA/Ao & $1.1 \pm 0.1$ & $1.1 \pm 0.1$ & $1.1 \pm 0.1$ & $1.1 \pm 0.1$ \\
\hline LVMI, (g/kg) & $1.4 \pm 0.3$ & $1.3 \pm 0.2$ & $1.5 \pm 0.2$ & $1.6 \pm 0.3$ \\
\hline $\mathrm{HR},(\mathrm{bpm})$ & $304.9 \pm 56.0$ & $342.8 \pm 65.2$ & $310.4 \pm 29.4$ & $307.5 \pm 31.9$ \\
\hline
\end{tabular}

\begin{tabular}{llll}
\hline Panel B & & & \\
Model & \multicolumn{1}{c}{$\begin{array}{c}\text { TS } \\
\text { TS }\end{array}$} & $\begin{array}{c}\text { 95\% Confidence interval } \\
\text { Spironolactone }\end{array}$ & $\begin{array}{c}\text { 95\% Confidence interval } \\
\text { Interaction of TS and } \\
\text { spironolactone }\end{array}$ \\
\hline BW & $-13.21(-31.37 ; 4.93)$ & $-4.88(-22.98 ; 13.20)$ & NONE \\
LVEDD/BW & $1.27(0.25 ; 2.30)^{*}$ & $-0.10(-1.10 ; 0.90)$ & NONE \\
LVESD/BW & $0.69(-0.15 ; 1.53)$ & $-0.16(-0.98 ; 0.65)$ & NONE \\
LVWT & $-0.007(-0.03 ; 0.18)$ & $0.01(-0.01 ; 0.04)$ & NONE \\
LA/Ao & $0.06(0.005 ; 0.11)^{*}$ & $0.008(-0.05 ; 0.06)$ & NONE \\
LVMI & $0.19(0.04 ; 0.34)^{*}$ & $0.002(-0.15 ; 0.15)$ & NONE \\
HR & $-15.33(-43.90 ; 13.22)$ & $16.23(-11.22 ; 43.68)$ & \\
\hline
\end{tabular}

Table 1. Echocardiographic morphological data. C: control animals; S: spironolactone animals; TS: animals exposed to tobacco smoke; BW: body weight; LVEDD: LV end-diastolic dimension; LVESD: LV end-systolic dimension; LVWT: LV posterior wall thickness; LA: left atrium; LV: left ventricle; LVMI: left ventricle mass index, HR: heart rate. Panel A: data are expressed as the mean \pm SD. Panel B: associations are expressed by regression coefficients and $95 \%$ confidence interval of the regression coefficients. ${ }^{*} \mathrm{p}<0.05$

\begin{tabular}{|c|c|c|c|c|c|}
\hline \multicolumn{6}{|l|}{ Panel A } \\
\hline Variables & $\begin{array}{c}\text { Group C } \\
n=11\end{array}$ & \multicolumn{2}{|c|}{$\begin{array}{c}\text { Group S } \\
n=12\end{array}$} & $\begin{array}{l}\text { Group TS-C } \\
n=13\end{array}$ & $\begin{array}{l}\text { Group TS-S } \\
\mathrm{n}=13\end{array}$ \\
\hline E wave, $(\mathrm{cm} / \mathrm{s})$ & $76.6 \pm 15.8$ & \multicolumn{2}{|c|}{$73.7 \pm 16.0$} & $78.6 \pm 12.1$ & $86.9 \pm 8.4$ \\
\hline A wave, $(\mathrm{cm} / \mathrm{s})$ & $52.5 \pm 18.6$ & \multicolumn{2}{|c|}{$66.7 \pm 15.2$} & $56.6 \pm 14.3$ & $54.5 \pm 10.9$ \\
\hline IVRT/RR ${ }^{0,5},(\mathrm{~ms})$ & $50.2 \pm 7.7$ & \multicolumn{2}{|c|}{$45.2 \pm 8.7$} & $56.0 \pm 8.5$ & $58.3 \pm 6.8$ \\
\hline FS, (\%) & $53.6 \pm 5.9$ & \multicolumn{2}{|c|}{$56.6 \pm 7.1$} & $54.8 \pm 4.9$ & $54.0 \pm 4.9$ \\
\hline $\mathrm{EF},(\%)$ & $89.6 \pm 3.6$ & \multicolumn{2}{|c|}{$91.2 \pm 4.2$} & $90.5 \pm 3.1$ & $89.9 \pm 3.3$ \\
\hline \multicolumn{6}{|l|}{ Panel B } \\
\hline Model & \multicolumn{2}{|c|}{$\begin{array}{l}95 \% \text { Confidence interval } \\
\text { TS }\end{array}$} & \multicolumn{2}{|c|}{$\begin{array}{l}\text { 95\% Confidence interval } \\
\text { Spironolactone }\end{array}$} & $\begin{array}{l}\text { 95\% Confidence interval } \\
\text { Interaction of TS and } \\
\text { spironolactone }\end{array}$ \\
\hline E wave & \multicolumn{2}{|c|}{$7.75(-0.16 ; 15.66)$} & \multicolumn{2}{|c|}{$3.01(-4.70 ; 10.75)$} & NONE \\
\hline A wave & \multicolumn{2}{|c|}{$-4.17(-13.1 ; 4.76)$} & \multicolumn{2}{|c|}{$5.56(-3.25 ; 14.38)$} & NONE \\
\hline IVRT/RR 0,5 & \multicolumn{2}{|c|}{$9.48(4.80 ; 14.16)^{*}$} & \multicolumn{2}{|c|}{$-1.12(-5.78 ; 3.53)$} & NONE \\
\hline FS & \multicolumn{2}{|c|}{$-0.73(-4.10 ; 2.65)$} & \multicolumn{2}{|c|}{$0.95(-2.36 ; 4.26)$} & NONE \\
\hline $\mathrm{EF}$ & \multicolumn{2}{|c|}{$-0.21(-2.29 ; 1.88)$} & \multicolumn{2}{|c|}{$0.48(-1.57 ; 2.54)$} & NONE \\
\hline
\end{tabular}

Table 2. Echocardiographic functional data. C: control animals; S: spironolactone animals; TS: animals exposed to tobacco smoke; E wave: peak velocity of early ventricular filling; A wave: peak velocity of transmitral flow during atrial contraction; IVRT/RR ${ }^{0,5}$ : isovolumetric relaxation time corrected by heart rate; FS: fractional shortening; EF: ejection fraction. Panel A: data are expressed as the mean \pm SD. Panel B: associations are expressed by regression coefficients and 95\% confidence interval of the regression coefficients. ${ }^{*} \mathrm{p}<0.05$

\section{Results}

The echocardiographic data are listed in Tables 1 and 2. There were no interactions between tobacco smoke exposure and spironolactone. However, the TS groups showed left chamber enlargement and a higher left ventricular mass index compared with the non-TS 
Santos/Nogueira/Rafacho et al.: Spironolactone and Tobacco Smoke Exposure

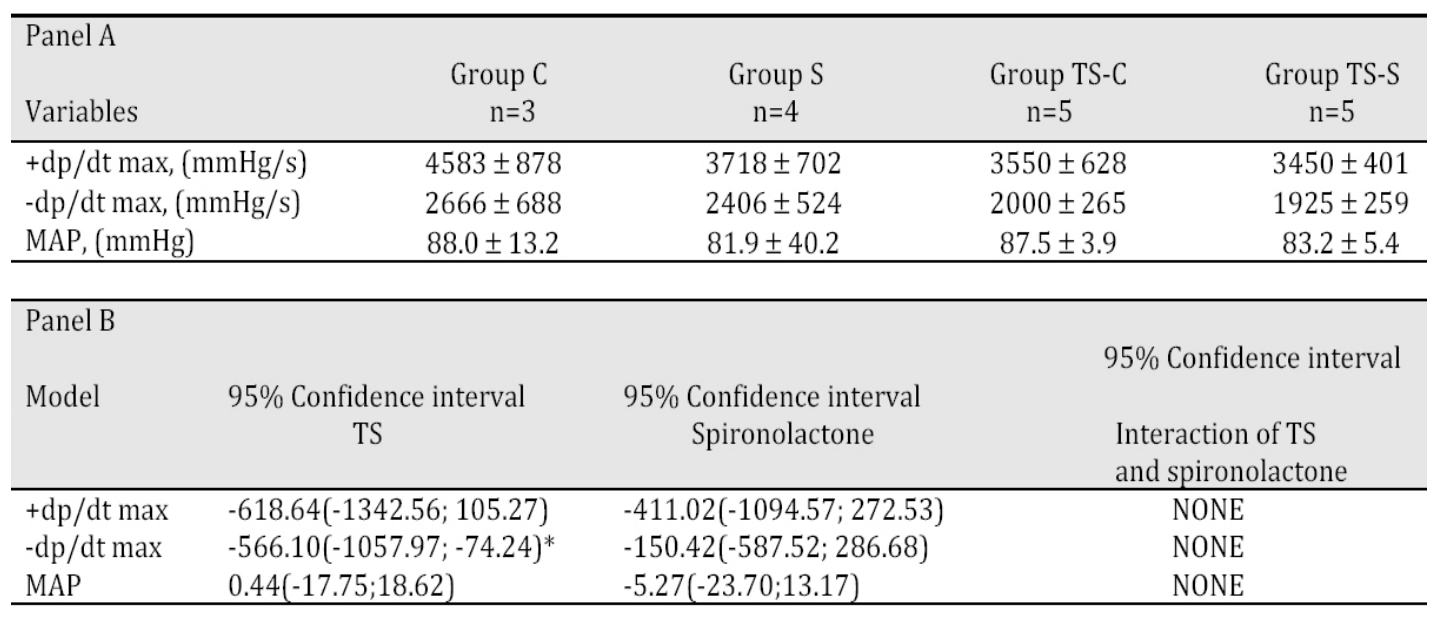

Table 3. In vitro left ventricular function data. C: control animals; S: spironolactone animals; TS: animals exposed to tobacco smoke; $+\mathrm{dp} / \mathrm{dt}$ max: maximum rate of ventricular pressure rise; -dp/dt max: decreased maximum rate of ventricular pressure rise; MAP: mean arterial pressure. Panel A: data are expressed as the mean \pm SD. Panel B: associations are expressed by regression coefficients and $95 \%$ confidence interval of the regression coefficients. $*$ p $<0.05$

\begin{tabular}{|c|c|c|c|c|}
\hline \multicolumn{5}{|l|}{ Panel A } \\
\hline Variables & $\begin{array}{c}\text { Group C } \\
n=8\end{array}$ & $\begin{array}{c}\text { Group S } \\
n=8\end{array}$ & $\begin{array}{c}\text { Group TS-C } \\
n=8\end{array}$ & $\begin{array}{c}\text { Group TS-S } \\
n=8\end{array}$ \\
\hline LVW/BW, (g/mg) & $1.7 \pm 0.2$ & $1.7 \pm 0.1$ & $2.1 \pm 0.1$ & $2.0 \pm 0.2$ \\
\hline RVW/BW, (g/mg) & $0.50 \pm 0.12$ & $0.45 \pm 0.08$ & $0.62 \pm 0.08$ & $0.56 \pm 0.09$ \\
\hline RVWC, $(\%)$ & $76.7 \pm 5.8$ & $76.1 \pm 1.8$ & $77.9 \pm 3.8$ & $74.2 \pm 7.4$ \\
\hline Lung WC, $(\%)$ & $72.8 \pm 2.6$ & $74.7 \pm 1.4$ & $77.4 \pm 1.3$ & $76.7 \pm 1.9$ \\
\hline Liver WC, (\%) & $67.1 \pm 0.9$ & $66.3 \pm 2.3$ & $69.2 \pm 1.1$ & $69.0 \pm 1.4$ \\
\hline IC, (\%) & $3.0 \pm 0.9$ & $3.0 \pm 0.5$ & $3.2 \pm 0.9$ & $2.8 \pm 0.4$ \\
\hline $\mathrm{CSA},\left(\mu \mathrm{m}^{2}\right)$ & $226.6 \pm 43.1$ & $218.6 \pm 28.3$ & $267.6 \pm 54.2$ & $252.0 \pm 53.8$ \\
\hline \multicolumn{5}{|l|}{ Panel B } \\
\hline Model & $\begin{array}{c}\text { 95\% Confidence interval } \\
\text { TS }\end{array}$ & \multicolumn{2}{|c|}{$\begin{array}{l}95 \% \text { Confidence interval } \\
\text { Spironolactone }\end{array}$} & $\begin{array}{c}95 \% \text { Confidence interval } \\
\text { Interaction of TS and } \\
\text { spironolactone }\end{array}$ \\
\hline $\mathrm{LVW} / \mathrm{BW}$ & $0.36(0.25 ; 0.48)^{*}$ & \multicolumn{2}{|c|}{$-0.09(-0.20 ; 0.02)$} & NONE \\
\hline RVW/BW & $0.11(0.04 ; 0.17)^{*}$ & \multicolumn{2}{|c|}{$-0.06(-0.12 ; 0.01)$} & NONE \\
\hline RVWC & $-0.32(-4.04 ; 3.40)$ & \multicolumn{2}{|c|}{$-2.24(-6.00 ; 1.53)$} & NONE \\
\hline Lung WC & $3.30(1.87 ; 4.73)^{*}$ & \multicolumn{2}{|c|}{$0.54(-0.87 ; 1.96)$} & NONE \\
\hline Liver WC & $2.36(1.24 ; 3.49)^{*}$ & \multicolumn{2}{|c|}{$-0.53(-1.66 ; 0.60)$} & NONE \\
\hline IC & $-0.0001(-0.005 ; 0.004)$ & \multicolumn{2}{|c|}{$-0.002(-0.006 ; 0.003)$} & NONE \\
\hline CSA & $59.17(29.81 ; 88.54)^{*}$ & \multicolumn{2}{|c|}{$43.95(15.92 ; 71.97)^{*}$} & NONE \\
\hline
\end{tabular}

Table 4. Morphological data. C: control animals; S: spironolactone animals; TS: animals exposed to tobacco smoke; S: spironolactone, BW: body weight; LVW: left ventricular weight; RVW: right ventricular weight; RVWC: right ventricular water content; WC: water content; IC: interstitial collagen volume fraction; CSA: cross-sectional area. Panel A: data are expressed as the mean \pm SD. Panel B: associations are expressed by regression coefficients and $95 \%$ confidence interval of the regression coefficients. ${ }^{*} \mathrm{p}<0.05$

groups. In addition to these morphological changes, tobacco smoke exposure led to a higher isovolumetric relaxation time corrected by heart rate. In accord with the echocardiography analysis, in vitro left ventricular diastolic function worsened in the TS groups and was not influenced by spironolactone administration (Table 3). 


\begin{tabular}{lcccc}
\hline Panel A & $\begin{array}{c}\text { Group C } \\
\mathrm{n}=8\end{array}$ & $\begin{array}{c}\text { Group S } \\
\mathrm{n}=8\end{array}$ & $\begin{array}{c}\text { Group TS-C } \\
\mathrm{n}=8\end{array}$ & $\begin{array}{c}\text { Group TS-S } \\
\mathrm{n}=8\end{array}$ \\
Variables & $3.8 \pm 1.2$ & $3.8 \pm 2.5$ & $3.9 \pm 1.1$ & $2.6 \pm 1.4$ \\
\hline TNF- $\alpha$, (pg/g of protein) & $6.9 \pm 1.9$ & $8.4 \pm 6.7$ & $7.0 \pm 1.8$ & $6.7 \pm 3.6$ \\
IFN- $\gamma$, (pg/g of protein) & $11.1 \pm 3.6$ & $7.7 \pm 7.2$ & $11.6 \pm 4.6$ & $6.9 \pm 4.9$ \\
IL-10, (pg/g of protein) & $83.8 \pm 27.8$ & $76.1 \pm 30.9$ & $102.0 \pm 28.4$ & $73.1 \pm 38.5$ \\
ICAM-1, (pg/g of & & & & \\
protein) & $0.15 \pm 0.06$ & $0.16 \pm 0.03$ & $0.22 \pm 0.08$ & $0.19 \pm 0.10$ \\
GLUT 4, (arbitrary units) &
\end{tabular}

\begin{tabular}{lccc}
\hline Panel B & 95\% Confidence interval & & \\
Model & TS & Confidence interval \\
Spironolactone & $\begin{array}{c}\text { 95\% Confidence interval } \\
\text { Interaction of TS and } \\
\text { spironolactone }\end{array}$ \\
\hline TNF- $\alpha$ & $-0.43(-1.60 ; 0.74)$ & $-0.66(-2.00 ; 0.69)$ & NONE \\
IFN- $\gamma$ & $-0.66(-3.36 ; 2.04)$ & $0.71(-2.56 ; 3.97)$ & NONE \\
IL-10 & $-0.43(-1.60 ; 0.74)$ & $-0.65(-1.99 ; 0.68)$ & NONE \\
ICAM-1 & $9.37(-13.16 ; 31.90)$ & $-17.45(-40.75 ; 5.85)$ & NONE \\
GLUT4 & $0.52(-0.007 ; 0.11)$ & $-0.01(-0.07 ; 0.05)$ & NONE \\
\hline
\end{tabular}

Table 5. Inflammatory cytokines, intercellular adhesion molecule 1 and GLUT4 data. C: control animals; S: spironolactone animals; TS: animals exposed to tobacco smoke; S: spironolactone; TNF- $\alpha$ : tumor necrosis factor- $\alpha$, IFN- $\gamma$ : interferon - $\gamma$; IL-10; ICAM-1: intercellular adhesion molecule 1, GLUT4: glucose transporter type 4. Panel A: data are expressed as the mean \pm SD. Panel B: associations are expressed by regression coefficients and $95 \%$ confidence interval of the regression coefficients. ${ }^{*} \mathrm{p}<0.05$

Regardless of the potential effects of tobacco and spironolactone on arterial pressure, there was no difference in invasive mean arterial pressure among the groups (Table 3).

The morphological data are listed in Table 4. The BW-corrected left ventricular weight (LVW) and BW-corrected right ventricular weight (RVW) were elevated in the TS group. In addition, the TS group had a larger myocyte cross-sectional area (CSA). Tobacco smoke exposure also increased the lung and liver water content. There were no interactions between TS and spironolactone in these morphometric variables. The interstitial collagen volume fraction was similar among the groups (Table 4).

Furthermore, TS and spironolactone administration did not affect myocardial levels of IFN- $\gamma$, TNF- $\alpha$, IL-10 and ICAM-1. Although the difference was not statistically significant, spironolactone reduced myocardial IL-10 and ICAM-1 despite tobacco smoke exposure (Table 5).

There was also no difference in GLUT4 expression among the groups (Table 5).

\section{Discussion}

Our study showed that tobacco smoke exposure induces morphological alterations and diastolic dysfunction in rats. In addition, these alterations were not related to inflammation or ICAM-1 or GLUT4 expression. Importantly, spironolactone does not influence ventricular remodeling induced by tobacco smoke exposure.

Consistent with previous reports, our data indicate that tobacco smoke exposure induces ventricular remodeling [3-10]. Currently, ventricular remodeling is defined as genome expression resulting in molecular, cellular and interstitial changes and manifested clinically as changes in the size, shape and function of the heart [26]. Although it can initially be a compensatory process, chronic ventricular remodeling leads to progressive ventricular dysfunction and sudden death [26]. 
One of the potential effects of aldosterone blockers is the inhibition of myocyte hypertrophy. Aldosterone stimulates hypertrophy by mechanical effects due to volume overload and direct effects due to myocyte growth. Okoshi et al. showed in serum-free culture of neonatal rat ventricular myocytes that aldosterone-induced hypertrophy was followed by increased mRNA levels of atrial natriuretic peptide and alpha- and beta-myosin heavy chains [17]. In addition, these alterations were attenuated by spironolactone [17]. Despite this potential effect, in this study, ventricular hypertrophy induced by tobacco smoke was not attenuated by spironolactone.

Spironolactone may also modulate the inflammatory process mediated by aldosterone. In other models of heart failure, increased production of cytokines, such as IFN- $\gamma$ and TNF$\alpha$, was associated with hypertrophy, fibrosis and left ventricular dysfunction $[27,28]$. Interestingly, tobacco smoke did not increase myocardial inflammatory cytokines in our study. Although we have already observed these cytokine patterns in previous studies, ICAM1 expression has not yet been evaluated in tobacco exposure models $[8,11]$. Importantly, the expression of adhesion molecules is essential for the influx of inflammatory cells into the myocardium. In addition, previous reports have shown that ICAM-1 expression increases after myocardial infarction [29]. However, in this study, myocardial ICAM-1 did not increase after tobacco smoke exposure. Surprisingly, although the difference was not statistically significant, spironolactone administration reduced myocardial concentrations of IL-10 and ICAM-1, despite tobacco smoke exposure.

The influence of tobacco exposure and spironolactone administration on insulin resistance was also evaluated. Smoking is a well-known risk factor for insulin resistance. However, the mechanisms responsible for smoking-induced insulin resistance are unclear. Tatebe and Morita showed in C2C12 skeletal myocytes that in the presence of palmitate, nicotine enhanced TNF- $\alpha$ expression, suppressed GLUT4 translocation to the plasma membrane and impaired glucose uptake into cells [30]. Rincón et al. also showed that insulinstimulated glucose transport is impaired in human skeletal muscle in smokers [31]. However, in this clinical study, the altered glucose uptake was not explained by altered GLUT4 protein expression but was related to increased serum free fatty acids and triglyceride levels [31].

Spironolactone can also influence insulin resistance. Human studies have shown an association between increased plasma levels of aldosterone and insulin resistance in patients with metabolic syndrome and primary aldosteronism [32, 33]. Some authors have suggested that this alteration is due to the pro-inflammatory effects of aldosterone [19]. In addition, Lastra et al. showed that spironolactone improves insulin-stimulated glucose transport and GLUT4 expression in the skeletal muscle of transgenic rats with increased RAAS activity [19]. In our study, left ventricular GLUT4 expression was not influenced by tobacco smoke exposure or spironolactone.

Finally, the mechanisms involved in ventricular remodeling induced by tobacco smoke exposure are not fully established. As discussed, MMPs have been implicated in cardiac remodeling. In fact, when rats with volume overload were exposed to tobacco smoke, there was increased expression of MMP-9 and TIMP-1 [34]. Another study demonstrated that trimetazidine protects against smoking-induced left ventricular remodeling via attenuating oxidative stress, apoptosis, and inflammation [35]. In addition, neurohormonal blockade is an interesting target for attenuating cardiac remodeling in this scenario. Indeed, administration of propranolol attenuated some of the variables of ventricular remodeling induced by smoking in rats [36]. In addition, a recent study conducted in our laboratory showed that lisinopril attenuated left ventricle enlargement, myocyte hypertrophy and systolic dysfunction due to tobacco smoke exposure [12]. However, in this study, spironolactone did not influence ventricular remodeling. Therefore, our data suggested that, differently of renin-angiotensin and adrenergic systems, aldosterone is not involved in ventricular remodeling induced by smoking.

In conclusion, our data do not support the participation of aldosterone in the ventricular remodeling process induced by exposed to cigarette smoke. 
Santos/Nogueira/Rafacho et al.: Spironolactone and Tobacco Smoke Exposure

\section{Conflict of Interest}

No conflict of interest declared.

\section{Acknowledgements}

This study was funded by the "Fundação de Amparo à Pesquisa do Estado de São Paulo" FAPESP (10/10187-2) and "Conselho Nacional de Desenvolvimento Científico e Tecnológico" CNPq (473091/2010-0).

\section{Reference}

1 Andrews JO, Tingen MS: The effect of smoking, smoking cessation, and passive smoke exposure on common laboratory values in clinical settings: A review of the evidence. Crit Care Nurs Clin N Am 2006;18:63-69.

2 Ockene IS, Miller NH: Cigarette smoking, cardiovascular disease, and stroke: a statement for healthcare professionals from the American Heart Association. American Heart Association Task Force on Risk Reduction. Circulation 1997;96:3243-3247.

3 Talukder MA, Johnson WM, Varadharaj S, Lian J, Kearns PN, El-Mahdy MA, Liu X, Zweier JL: Chronic cigarette smoking causes hypertension, increased oxidative stress, impaired NO bioavailability, endothelial dysfunction, and cardiac remodeling in mice. Am J Physiol Heart Circ Physiol 2011;300:H388-396.

4 Castardeli E, Duarte DR, Minicucci MF, Azevedo PS, Matsubara BB, Matsubara LS, Campana AO, Paiva SA, Zornoff LA: Exposure time and ventricular remodeling induced by tobacco smoke exposure in rats. Med Sci Monit 2008;14:BR62-66.

5 Castardeli E, Duarte DR, Minicucci MF, Azevedo PS, Matsubara BB, Matsubara LS, Campana AO, Paiva SA, Zornoff LA: Tobacco smoke-induced left ventricular remodelling is not associated with metalloproteinase2 or -9 activation. Eur J Heart Fail 2007;9:1081-1085.

6 Gu L, Pandey V, Geenen DL, Chowdhury SA, Piano MR: Cigarette smoke-induced left ventricular remodelling is associated with activation of mitogen-activated protein kinases. Eur J Heart Fail 2008;10:1057-1064.

7 Oliveira LC, Azevedo PS, Minicucci MF, Rafacho BP, Duarte DR, Matsubara LS, Matsubara BB, Paiva SA, Zornoff LA: Retinoic acid prevents ventricular remodelling induced by tobacco smoke exposure in rats. Acta Cardiol 2011;66:3-7.

8 Rafacho BP, Azevedo PS, Polegato BF, Fernandes AA, Bertoline MA, Fernandes DC, Chiuso-Minicucci F, Roscani MG, Dos Santos PP, Matsubara LS, Matsubara BB, Laurindo FR, Paiva SA, Zornoff LA, Minicucci MF: Tobacco smoke induces ventricular remodeling associated with an increase in NADPH oxidase activity. Cell Physiol Biochem 2011;27:305-312.

9 Rafacho BP, Santos P, Assalin HB, Ardisson LP, Roscani MG, Polegato BF, Chiuso-Minicucci F, Fernandes AA, Azevedo PS, Minicucci MF, Zornoff LA, Paiva S: Role of vitamin D in the cardiac remodeling induced by tobacco smoke exposure. Int J Cardiol 2012;155:472-473.

10 Denipote F, Ardisson LP, Azevedo PS, Minicucci MF, Lima-Leopoldo AP, Chiuso-Minicucci F, Polegato BF, Matsubara BB, Matsubara LS, Novelli E, Paiva SA, Zornoff LA: Influence of taurine on cardiac remodeling induced by tobacco smoke exposure. Cell Physiol Biochem 2011;27:291-298.

11 Duarte DR, Minicucci MF, Azevedo PS, Matsubara BB, Matsubara LS, Novelli EL, Paiva SA, Zornoff LA: The role of oxidative stress and lipid peroxidation in ventricular remodeling induced by tobacco smoke exposure after myocardial infarction. Clinics 2009;64:691-697.

12 Duarte DR, Minicucci MF, Azevedo PS, Chiuso-Minicucci F, Matsubara BB, Matsubara LS, Campana AO, Paiva SA, Zornoff LA: Influence of lisinopril on cardiac remodeling induced by tobacco smoke exposure. Med Sci Monit 2010;16:BR255-259. 
13 Jessup M, Abraham WT, Casey DE, Feldman AM, Francis GS, Ganiats TG, Konstam MA, Mancini DM, Rahko PS, Silver MA, Stevenson LW, Yancy CW: 2009 focused update: ACCF/AHA Guidelines for the Diagnosis and Management of Heart Failure in Adults: a report of the American College of Cardiology Foundation/ American Heart Association Task Force on Practice Guidelines: developed in collaboration with the International Society for Heart and Lung Transplantation. Circulation 2009;119:1977-2016.

14 Zannad F, McMurray JJ, Krum H, van Veldhuisen DJ, Swedberg K, Shi H, Vincent J, Pocock SJ, Pitt B, EMPHASIS-HF Study Group: Eplerenone in patients with systolic heart failure and mild symptoms. N Engl J Med 2011;364:11-21.

15 Krum H, Jelinek MV, Stewart S, Sindone A, Atherton JJ, National Heart Foundation of Australia; Cardiac Society of Australia and New Zealand: 2011 update to National Heart Foundation of Australia and Cardiac Society of Australia and New Zealand Guidelines for the prevention, detection and management of chronic heart failure in Australia, 2006. Med J Aust 2011;194:405-409.

16 McKelvie RS, Moe GW, Cheung A, Costigan J, Ducharme A, Estrella-Holder E, Ezekowitz JA, Floras J, Giannetti N, Grzeslo A, Harkness K, Heckman GA, Howlett JG, Kouz S, Leblanc K, Mann E, O’Meara E, Rajda M, Rao V, Simon J, Swiggum E, Zieroth S, Arnold JM, Ashton T, D’Astous M, Dorian P, Haddad H, Isaac DL, Leblanc MH, Liu P, Sussex B, Ross HJ: The 2011 Canadian Cardiovascular Society heart failure management guidelines update: focus on sleep apnea, renal dysfunction, mechanical circulatory support, and palliative care. Can J Cardiol 2011;27:319-338.

17 Okoshi MP, Yan X, Okoshi K, Nakayama M, Schuldt AJ, O’Connell TD, Simpson PC, Lorell BH: Aldosterone directly stimulates cardiac myocyte hypertrophy. J Card Fail 2004;10:511-518.

18 Satoh M, Nakamura M, Akatsu T, Shimoda Y, Segawa I, Hiramori K: C-reactive protein co-expresses with tumor necrosis factor-alfa in the myocardium in humam dilated cardiomyopathy. Eur J Heart Fail 2005; 7:748-754.

19 Lastra G, Whaley-Connell A, Manrique C, Habibi J, Gutweiler AA, Appesh L, Hayden MR, Wei Y, Ferrario C, Sowers JR: Low-dose spironolactone reduces reactive oxygen species generation and improves insulinstimulated glucose transport in skeletal muscle in the TG(mRen2)27 rat. Am J Physiol Endocrinol Metab 2008;295:E110-116.

20 Wang XD, Liu C, Bronson RT, Smith DE, Krinsky NI, Russell M: Retinoid signaling and activator protein-1 expression in ferrTS given b-carotene supplements and exposure to tobacco smoke. J Natl Cancer Inst 1999;91:60-66.

21 Paiva SAR, Zornoff LAM, Okoshi MP, Okoshi K, Matsubara LS, Matsubara BB, Cicogna AC, Campana AO: Ventricular remodeling induced by retinoic acid supplementation in adult rats. Am J Physiol 2003;284: H2242-2246.

22 Lang RM, Bierig M, Devereaux RB, Flachskampf FA, Foster E, Pellikka PA, Picard MH, Roman MJ, Seward J, Shanewise JS, Solomon SD, Spencer KT, Sutton MS, Stewart WJ, Chamber Quantification Writing Group; American Society of Echocardiography's Guidelines and Standards Committee, European Association of Echocardiography: Recommendations for chamber quantification: a report from the American Society of Echocardiography's Guidelines and Standards Committee and the Chamber Quantification Writing Group, developed in conjunction with the European Association of Echocardiography, a branch of the European Society of Cardiology. J Am Soc Echocardiogr 2005;18:1440-1463.

23 Paiva SA, Novo R, Matsubara BB, Matsubara LS, Azevedo PS, Minicucci MF, Campana AO, Zornoff LA: $\beta$-carotene attenuates the paradoxical effect of tobacco smoke on the mortality of rats after experimental myocardial infarction. J Nutr 2005;135:2109-2113.

24 Minicucci MF, Azevedo PS, Oliveira AS Jr, Martinez PF, Chiuso-Minicucci F, Polegato BF, Justulin LA Jr, Matsubara LS, Matsubara BB, Paiva SA, Zornoff LA: Tissue vitamin A insufficiency results in adverse ventricular remodeling after experimental myocardial infarction. Cell Physiol Biochem 2010;26:523-530.

25 Azevedo PS, Minicucci MF, Chiuso-Minicucci F, Justulin LA Jr, Matsubara LS, Matsubara BB, Novelli E, Seiva F, Ebaid G, Campana AO, Zornoff LA, Paiva SA: Ventricular remodeling induced by tissue vitamin a deficiency in rats. Cell Physiol Biochem 2010;26:395-402.

26 Zornoff LA, Paiva SA, Duarte DR, Spadaro J: Ventricular remodeling after myocardial infarction: concepts and clinical implications. Arq Bras Cardiol 2009;92:157-164.

27 Bryant D, Becker L, Richardson J, Shelton J, Franco F, Peshock R, Thompson M, Giroir B: Cardiac failure in transgenic mice with myocardial expression of tumor necrosis factor- $\alpha$. Circulation 1998;97:1375-1381. 
28 Mann DL: Tumor necrosis factor-induced signal transduction and left ventricular remodeling. J Card Fail 2002;8: S379-384.

29 Kawamura A, Miura S, Murayama T, Iwata A, Nishikawa H, Matsuo Y, Matsuo Y, Tsuchiya Y, Matsuo K, Tsuji E, Saku K: Changes in the expression of leukocyte adhesion molecules throughout the acute phase of myocardial infarction. J Atheroscler Thromb 2004;11:29-34.

30 Tatebe J, Morita T: Enhancement of TNF- $\alpha$ expression and inhibition of glucose uptake by nicotine in the presence of a free fatty acid in C2C12 skeletal myocytes. Horm Metab Res 2011;43:11-16.

31 Rincón J, Krook A, Galuska D, Wallberg-Henriksson H, Zierath JR: Altered skeletal muscle glucose transport and blood lipid levels in habitual cigarette smokers. Clin Physiol 1999;19:135-142.

32 Bochud M, Nussberger J, Bovet P, Maillard MR, Elston RC, Paccaud F, Shamlaye C, Burnier M: Plasma aldosterone is independently associated with the metabolic syndrome. Hypertension 2006;48:239-245.

33 Fallo F, Veglio F, Bertello C, Sonino N, Mea PD, Ermani M, Rabbia F, Federspil G, Mulatero P: Prevalence and characteristics of the metabolic syndrome in primary aldosteronism. J Clin Endocrinol Metab 2006;91:454-459.

34 Bradley JM, Nguyen JB, Fournett AC, Gardner JD: Cigarette smoke exacerbates ventricular remodeling and dysfunction in the volume overloaded heart. Microsc Microanal 2012;18:91-98.

35 Zhou X, Li C, Xu W, Chen J: Trimetazidine Protects against Smoking-Induced Left Ventricular Remodeling via Attenuating Oxidative Stress, Apoptosis, and Inflammation. PLoS One 2012;7:e40424.

36 Duarte DR, Oliveira LC, Minicucci MF, Azevedo PS, Matsubara BB, Matsubara LS, Campana AO, Paiva SA, Zornoff LA: Effects of the administration of beta-blockers on ventricular remodeling induced by cigarette smoking in rats. Arq Bras Cardiol 2009;92:443-447. 